\title{
Family physicians urge creation of "medical homes" for every Canadian
}

Previously published at www.cmaj.ca

$\mathrm{T}$ hey have become all the rage in America and, as another adage goes, may be coming soon to a theatre near you.

United States President Barack Obama wants to fund a raft of pilot patient-centred "medical homes." A Seattle, Washington-based health maintenance organization is converting 26 of its existing clinics so that they conform to the much-ballyhooed model of delivering health care. In 2007, Vermont passed legislation creating a host of new medical homes for the chronically ill, which would "bring together patients who will learn how to manage their conditions, providers who will oversee the patients' care, a health care team to provide individualized support to the patient, and patients' local communities." Doctors in Pennsylvania and New Jersey are implementing the model in an American Academy of Family Physicians demonstration project. An insurer in Illinois is enrolling 20000 patients with chronic diseases into a pilot program.

The list goes on and on.

Although skeptical patients might consider it nothing short of science fiction, proponents cast it as a model of health care delivery that is altogether user-friendly, in which doctors and nurses, for example, actively contact patients to inquire about side effects of medications or remind them of the need to watch their trans fat intake.

At its core, the model is teambased approach to providing comprehensive primary care, in which there is a fundamental shift in the relationship between health care providers and patients that essentially allows for around-the-clock access to medical advice, which is coordinated with other community services and is culturally sensitive.

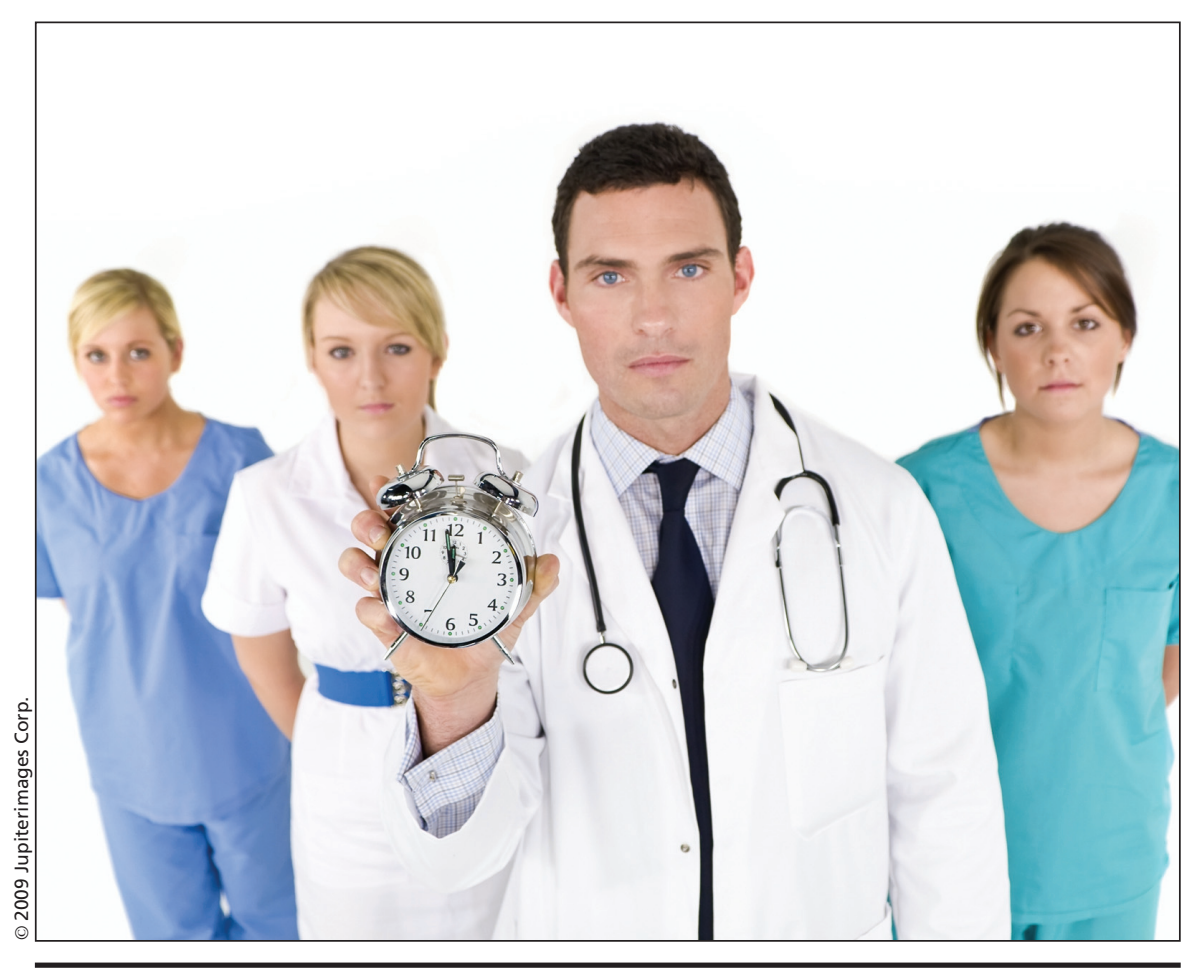

The time has come for a fundamental shift in the relationship between health care providers and patients that essentially allows for around-the-clock access to medical advice that is coordinated with other community services and is culturally sensitive, a College of Family Physicians of Canada discussion paper says.

The model proposes to link an average patient who is feeling lost and homeless within a health care system with a personal physician (and therein, a team of other health care providers, nutritionists, social workers, etc.) who would guide the patient through the process of actually receiving effective care and also ensure that all the requisite bits and pieces are put in place to ensure that the needed care is provided over the course of that patient's lifetime.

Under the model, doctors receive per-patient, per-month payments (varying according to the underlying illness) for coordinating a patient's care and a bonus if desirable health outcomes are achieved - if a diabetic patient loses weight, for example.

The American Association of Pedi- atrics (AAP) is credited with crafting the concept in 1992, but an array of medical associations has since clambered aboard and refined the notion, including the American College of Physicians and the American Academy of Family Physicians, which, along with the AAP, in March 2007, issued a statement of "joint principles" for a preferred medical home framework (pcpcc.net/content/joint-principles-patient -centered-medical-home). The Association of American Medical Colleges last year said that while it will require curriculum and training changes, "the medical home model holds great promise for improving the health of populations and individuals" (www.aamc.org/newsroom /pressrel/2008/medicalhome.pdf).

Joining the chorus on Oct. 29 was the College of Family Physicians of 
Canada (CFPC) as it released a discussion paper, Patient-Centred Primary Care in Canada: Bring It On Home, and called on governments to establish a medical home, led by a family doctor, for every Canadian, not just chronically ill ones.

"A medical home keeps the focus on the experience of the patient, rather than systems or networks. The place where people receive their care should feel like a home, give patients a sense of comfort, confidence and support," CFPC President Dr. Sarah Kredentser said during a webcast press conference.

Kredentser argued that the medical home concept should also be appealing to politicians because it would yield a more cost-effective health care system. "Lots of research out there shows that a strong primary care system reduces costs, reduces emergency room visits and has overall better outcomes for patients. That's where you are going to get the biggest bang for your buck in health care dollars."

Executive Director and Chief Executive Officer Dr. Calvin Gutkin added that CFPC envisions medical homes that are much more comprehensive than any of the array of team-based primary care delivery models that are perhaps, might be best understood today, when our communities are facing situations like our current H1N1 challenges," Gutkin said.

The CFPC identified the requisite components of a medical home as being:

- Patient-centred to meet the range of health needs that patients experience over a lifetime

- Team-based care, including both 1) inter-professional collaboration that includes the patient's family physician and other health professionals, and 2) intra-professional collaboration (i.e. between the patient's personal family physician, other family physicians with special interests and skills, and other consulting specialists)

- Timely access to care, for both primary care visits and referrals for more highly specialized services and consultations; achieve through both face-to-face visits as well as through electronic communications between patients and providers

- Comprehensive, continuous care "from cradle to grave" through appropriate linkages between primary care and other parts of the health system, and between the patient's family physician and other healthcare providers

\section{"The place where people receive their care} should feel like a home, give patients a sense of comfort, confidence and support." - College of Family Physicians of Canada President Dr. Sarah Kredentser.

now being established in various provinces, such as physician-integrated networks, family health teams, integrated network clinics and family health centres.

All of those are "missing ingredients that would enable these practices to become the one-stop centres that can address all of the medical care needs of their patients. These needs include both the direct provision and referral for medical care, from prevention to treatment - needs that
- Electronic medical and health records

- Appropriate funding and remuneration to support the medical home and its professional team members

- Ongoing evaluation of outcomes/ quality improvement programs."

The discussion paper calls for "appropriate funding and remuneration to support the medical home and its professional team members." It notes the model of remuneration for doctors involved in medical homes is basically incompatible with fee-for-service arrangements and more in line with payment models being adopted in conjunction with team-based delivery models that are being created across Canada as a consequence of massive federal investments over the past decade. In Ontario's Family Health Networks, for example, family physicians "receive enrolment funding per patient, $10 \%$ of applicable FFS [feefor-service] billing codes, several targeted payments, and FFS for nonenrolled patients."

Such "blended" payment mechanisms appear to be more applicable to achieving such goals as preventative health and providing care to more diverse populations, the paper adds. "They also allow family physicians the opportunity to spend enough time with those patients whose needs are more complex. Payments based on meeting specific preventive health targets can also be included. While pay-forperformance is a concern if it leads to direct care to only meet certain indicators, incentives for meeting preventive care targets combined with the ability to identify them on an electronic medical record may be beneficial."

The paper also notes that funding would have to be provided to ensure that certain systemic changes are made, including "sufficient health human resources; adequate funding and clearly defined liability protection for all team members; system support for electronic health record systems; agreements from each health care profession about the clinical, and organization roles and responsibilities for all team members, and; establishment of links/networks with other health professionals and hospitals in the community."

The CFPC also indicated that its internal tracking indicates that some progress is being made toward achieving the target of ensuring that every Canadian has a family physician by 2012 .

In 2007, $15 \%$ of Canadians lacked a family physician, but that's now been reduced to $12 \%$, said CFPC Presidentelect Dr. Cathy MacLean. "But that still leaves four million in Canada without." - Wayne Kondro, CMAJ

DOI:10.1503/cmaj.109-3098 